\title{
Incidence of gallstones after gastric resection for gastric cancer: a nationwide claims-based study
}

\author{
Gi Hyeon Seo', Chang-Sup Lim², Young Jun Chai ${ }^{2}$ \\ ${ }^{1}$ Health Insurance Review and Assessment Service, Wonju, Korea \\ ${ }^{2}$ Department of Surgery, Seoul Metropolitan Government - Seoul National University Boramae Medical Center, Seoul National \\ University College of Medicine, Seoul, Korea
}

\begin{abstract}
Purpose: Gallstone formation is one of the most common problems after gastrectomy. This retrospective cohort study used the South Korean nationwide claims database to evaluate the incidence and risk factors of gallstone after gastrectomy for gastric cancer.

Methods: All consecutive patients who underwent gastrectomy for gastric cancer in South Korea in 2008-2010 were identified. Incidence of gallstone formation 5 years after gastrectomy in males and females, in various age groups, and after different types of gastrectomy was determined. Multivariate logistic regression analysis served to identify gallstone risk factors.

Results: Of the 47,752 patients, 2,506 (5.2\%) developed gallstone during the 5-year follow-up period. At 12, 24, 36, and 48 months, the cumulative incidences were $1.2 \%, 2.2 \%, 3.3 \%$, and $4.3 \%$, respectively. Males had a higher incidence than females (5.8\% vs. 4.1\%, P < 0.001). Older patients (60-89 years) had a higher incidence than younger patients (30-59 years) (6.1\% vs. $4.3 \%, \mathrm{P}<0.001)$. Gallstone was most common after total gastrectomy (6.6\%), followed by proximal gastrectomy $(5.4 \%)$, distal gastrectomy $(4.8 \%)$, and pylorus-preserving distal gastrectomy $(4.0 \%)(P<0.001)$. Multivariate analysis showed that male sex (odds ratio [OR], 1.39), an older age (OR, 1.44), and total gastrectomy (OR, 1.40 vs. distal gastrectomy) were significant independent risk factors for postgastrectomy gallstone.

Conclusion: The cumulative incidence of gallstone 5 years after gastrectomy for gastric cancer was $5.2 \%$. Male sex, an older age, and total gastrectomy were significant risk factors. More careful monitoring for gallstone may be necessary in patients with such risk factors.

[Ann Surg Treat Res 2018;95(2):87-93]
\end{abstract}

Key Words: Gallstones, Gastrectomy, Stomach neoplasms, Cholecystectomy

\section{INTRODUCTION}

In South Korea, gastric cancer is the second most commonly diagnosed cancer [1]. However, due to improvements in surgical techniques and perioperative patient management, patients with gastric cancer are increasingly surviving for longer periods $[1,2]$. Therefore, it is necessary to pay more attention to factors that may affect quality of life after surgery. One such factor is the formation of gallstones. Patients who undergo gastrectomy have a higher incidence of gallstones than the general population [2-5]. While the etiology of gallstone formation after gastrectomy has not yet been elucidated fully, possible causes may be severance of the hepatic branch of the vagal nerve, nonphysiological reconstruction of the gastrointestinal tract,
Received October 17, 2017, Revised December 11, 2017,

Accepted January 2, 2018

\section{Corresponding Author: Chang-Sup Lim}

Department of Surgery, Seoul Metropolitan Government - Seoul National University Boramae Medical Center, Seoul National University College of Medicine, 20 Boramae-ro 5-gil, Dongjak-gu, Seoul 07061, Korea Tel: +82-2-870-3291, Fax: +82-2-831-2826

E-mail: limcs7@gmail.com

ORCID code: https://orcid.org/0000-0002-2349-9647
Copyright (C) 2018, the Korean Surgical Society

(c) Annals of Surgical Treatment and Research is an Open Access Journal. All articles are distributed under the terms of the Creative Commons Attribution NonCommercial License (http://creativecommons.org/licenses/by-nc/4.0/) which permits unrestricted non-commercial use, distribution, and reproduction in any medium, provided the original work is properly cited. 
and an altered response to cholecystokinin secretion [3].

In experienced hands, it is not excessively difficult to perform cholecystectomy in patients who previously underwent gastrectomy. In fact, several studies reported the feasibility and safety of laparoscopic cholecystectomy after gastrectomy [2,6-12]. However, it is still a technically demanding procedure because of the likely presence of adhesions between the gallbladder and the abdominal wall or Calot triangle. These adhesions complicate the access to the gallbladder and increase the risk of iatrogenic injury during the operation [3,10]. In this regards, it is notable that a prospective multicenter study recommended prophylactic cholecystectomy during gastrectomy as it was not associated with increased postoperative morbidity [13].

It is important to understand the incidence and risk factors of gallstones after gastrectomy because this may help surgeons to determine the optimal postoperative monitoring strategy for patients after gastrectomy. To address this issue, we conducted a retrospective analysis of the South Korean nationwide insurance claims database to estimate the incidence of and risk factors for gallstones after gastrectomy for gastric cancer.

\section{METHODS}

\section{Data acquisition}

This retrospective cohort study was based on the Health Insurance Review and Assessment Service (HIRA) database. All people who reside in South Korea are obliged to enroll themselves in the single government-established health insurance system. Therefore, the HIRA database contains nearly $100 \%$ of all medical claims in South Korea since January 2007. It contains patient records that indicate patient age and gender, diagnoses, interventions, and operations [14].

The study protocol was approved by the Institutional Review Board of the Seoul Metropolitan Government - Seoul National University Boramae Medical Center (approval number: SMG-SNUH 07-2017-1/012), and the study was conducted in accordance with the Declaration of Helsinki. The requirement for informed consent was waived due to the retrospective nature of the study.

\section{Patient selection and classification}

All consecutive patients aged between 30 and 89 who underwent gastrectomy for malignant neoplasm of the stomach between January 2008 and December 2010 were identified in the HIRA database by searching for the primary or secondary International Statistical Classification of Diseases, 10th revision (ICD-10) diagnostic codes C16.1-C16.9. Only patients who underwent distal gastrectomy (Q0252 and Q0253), pyloruspreserving distal gastrectomy (Q0254 and Q0255), proximal gastrectomy (Q0258 and Q2598), and total gastrectomy (Q2533, Q2534, Q2536, and Q2537) were selected for analysis. Those with partial resection (Q0251 and Q2594) or wedge resection (Q0256 and Q0257) were excluded because information regarding the resection site was not available.

We used the data registered in the HIRA database until December 2015, and the last follow-up date was defined as the last claim data registered. As such, patients enrolled from January 2008 had maximum 8 years of follow-up, and those enrolled from December 2010 had maximum 5 years of followup. The new formation of gallstones during the 5 -year follow-up period was identified by searching for the ICD-10 classification codes K80.0-K80.5, and K80.8, which indicate gallstone disease. The date of gallstone occurrence was defined as the registration date of these diagnostic codes. The patients who had these gallstone diagnostic codes before or during hospitalization for their gastrectomy (i.e., between January 2007 and the date of gastrectomy) were excluded from the cohort.

The patients who developed gallstones after gastrectomy and who underwent cholecystectomy (Q7380) with or without choledochotomy with common bile duct stone removal (Q7310) after their gallstone diagnosis were identified by searching the HIRA database.

\section{Statistical analysis}

To determine the influence of sex, age, and gastrectomy type on gallstone incidence, the patients were first divided into groups according to new gallstone occurrence after gastrectomy. These groups were then subdivided according to sex, age group (30-49, 50-59, 60-69, and 70-89), and type of operation (distal, pylorus-preserving, proximal, and total gastrectomy). Categorical variables were expressed as number and percentage, while continuous variables were expressed as mean with standard deviation. The groups were compared in terms of categorical and continuous variables using chi-square test or Student t-test, as appropriate. The cumulative incidence of gallstone in the patients at risk was evaluated using KaplanMeier plotting. Multivariate logistic regression was used to identify which variables associate independently with risk of gallstone after gastrectomy. The data are expressed as odds ratios (OR) and 95\% confidence intervals (CIs). All statistical analyses were performed using R 3.2.2 (R Development Core Team; R Foundation for Statistical Computing, Vienna, Austria), and P-values less than 0.05 were considered to indicate statistical significance.

\section{RESULTS}

In total, 52,870 patients underwent gastrectomy for gastric cancer in 2008-2010. Of these, 5,118 (9.7\%) were excluded because they underwent partial resection $(n=1,725)$ or wedge resection $(n=587)$ or had been diagnosed with gallstones before or during hospitalization for gastrectomy $(n=2,806$ ). 
Table 1. Demographic and clinical characteristics of the whole cohort and the patients who did and did not develop postgastrectomy gallstone

\begin{tabular}{|c|c|c|c|c|}
\hline Variable & Gallstone (+) & Gallstone $(-)$ & Total & P-value \\
\hline No. of patients & $2,506(5.2)$ & $45,246(94.8)$ & 47,752 & \\
\hline \multicolumn{5}{|l|}{ Sex } \\
\hline Male & $1,853(5.8)$ & $30,131(94.2)$ & 31,984 & $<0.001$ \\
\hline Female & $653(4.1)$ & $15,115(95.9)$ & 15,768 & \\
\hline \multicolumn{5}{|l|}{ Age $(y r)$} \\
\hline $30-49$ & $379(3.7)$ & $9,767(96.3)$ & 10,146 & $<0.001$ \\
\hline $50-59$ & $578(4.7)$ & $11,642(95.3)$ & 12,220 & \\
\hline $60-69$ & $840(5.8)$ & $13,723(94.2)$ & 14,563 & \\
\hline $70-89$ & $709(6.6)$ & $10,114(93.4)$ & 10,823 & \\
\hline Type of operation & & & & $<0.001$ \\
\hline Distal gastrectomy & $1,668(4.8)$ & $33,062(95.2)$ & 34,730 & \\
\hline Pylorus-preserving distal gastrectomy & $22(4.0)$ & $530(96.0)$ & 552 & \\
\hline Proximal gastrectomy & $41(5.4)$ & $718(94.6)$ & 759 & \\
\hline Total gastrectomy & $775(6.6)$ & $10,936(93.4)$ & 11,711 & \\
\hline
\end{tabular}

Values are presented as number (\%).

The remaining 47,752 patients formed the study cohort. Of these, $31,984(67.0 \%)$ were male and $15,768(30.0 \%)$ were female patients. The mean age was $59.6 \pm 11.6$ years. The most common age group was $60-69$ years $(30.5 \%)$, followed by the 50-59 (25.6\%), 70-89 (22.7\%), and 30-49 (21.3\%) year age groups. Distal gastrectomy was the most commonly performed operation $(72.7 \%)$, followed by total gastrectomy (24.5\%). Pyloruspreserving and proximal gastrectomy together accounted for $2.8 \%$ of all gastrectomies (Table 1).

During the 5-year follow-up after gastrectomy, 2,506 patients (5.2\%) were newly diagnosed with gallstones. The cumulative incidence at $12,24,36,48$, and 60 months was $1.2 \%(n=575)$, $2.2 \%(\mathrm{n}=1,072), 3.3 \%(\mathrm{n}=1.571), 4.3 \%(\mathrm{n}=2,070)$, and $5.2 \%$ ( $\mathrm{n}=2,506)$, respectively. As shown in Table 1, male patients were more likely to develop gallstones after gastrectomy than females $(5.8 \%$ vs. $4.1 \%, \mathrm{P}<0.001)$. The incidence of postgastrectomy gallstones rose steadily with age (from 3.7\% in $30-49$ years to $6.6 \%$ in $70-89$ years, $P<0.001$ ). Postgastrectomy gallstones occurred most frequently in patients who underwent total gastrectomy, followed by proximal gastrectomy, distal gastrectomy, and pylorus-preserving distal gastrectomy $(6.6 \%$, $5.4 \%, 4.8 \%$, and $4.0 \%$, respectively, $\mathrm{P}<0.001$ ).

Multivariate logistic regression analysis showed that male sex (OR, 1.39; 95\% CI, 1.27-1.52), an older age (60-89 years relative to $30-59$ years: $O R, 1.44 ; 95 \% \mathrm{CI}, 1.33-1.57)$, and total gastrectomy (relative to distal gastrectomy: OR, 1.40; 95\% CI, 1.28-1.58) were significant independent risk factors for gallstones after gastrectomy (Table 2). The cumulative incidences of postgastrectomy gallstones in these high-risk groups relative to the low-risk groups are shown in Fig. 1.

To determine whether pylorus preservation affected the postgastrectomy development of gallstones, the patients who
Table 2. Multivariate analysis of risk factors for gallstone after gastrectomy

\begin{tabular}{lcr}
\hline \multicolumn{1}{c}{ Variable } & $\begin{array}{c}\text { Odds ratio (95\% } \\
\text { confidence interval) }\end{array}$ & P-value \\
\hline Sex & 1 & \\
Female & & \\
Male & $1.39(1.27-1.52)$ & $<0.001$ \\
Age $(\mathrm{yr})$ & 1 & \\
$30-59$ & $1.44(1.33-1.57)$ & $<0.001$ \\
$60-89$ & 1 & \\
Type of operation & & \\
$\begin{array}{l}\text { Distal gastrectomy } \\
\text { Pylorus-preserving } \\
\text { distal gastrectomy }\end{array}$ & $0.85(0.55-1.30)$ & 0.448 \\
$\quad$ Proximal gastrectomy & $1.10(0.80-1.51)$ & 0.555 \\
Total gastrectomy & $1.40(1.28-1.53)$ & $<0.001$ \\
\hline
\end{tabular}

underwent pylorus-preserving gastric resection (i.e., pyloruspreserving distal gastrectomy and proximal gastrectomy) were compared with the patients who underwent pylorus-resecting gastric resection (i.e., distal gastrectomy and total gastrectomy). Gallstones developed in 63 of the 1,311 pylorus-preserved patients (4.8\%) and in 2,443 of the 46,441 pylorus-resected patients $(5.3 \%)$. This difference did not achieve statistical significance $(\mathrm{P}=0.506)$.

Of the 2,506 patients who developed postgastrectomy gallstones, $662(26.4 \%)$ underwent cholecystectomy during follow-up. The majority $(\mathrm{n}=540,81.6 \%)$ underwent cholecystectomy alone. The remainder $(\mathrm{n}=122,18.4 \%)$ underwent cholecystectomy with common bile duct stone removal via choledochotomy. 
A

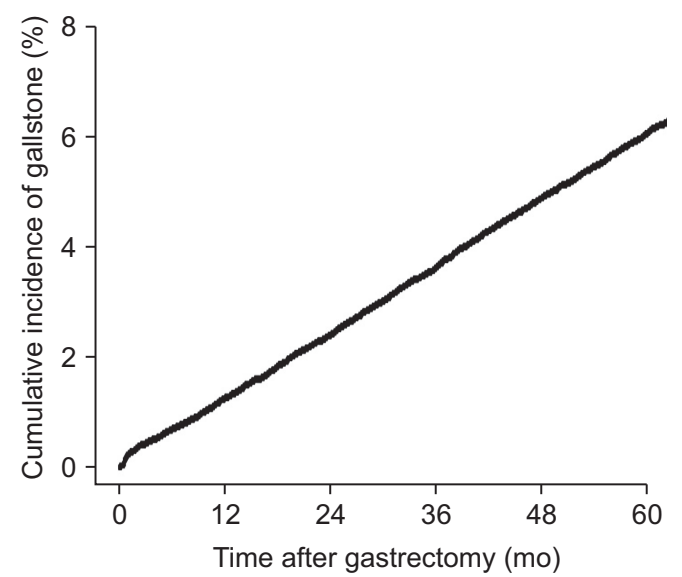

No. at risk $\quad 47,752 \quad 44,283 \quad 40,975 \quad 38,482 \quad 36,478 \quad 34,702$
B

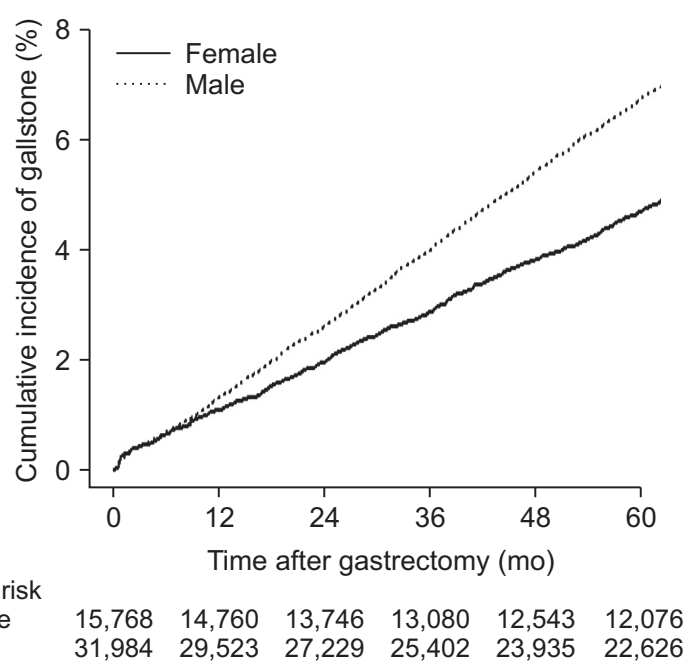

D

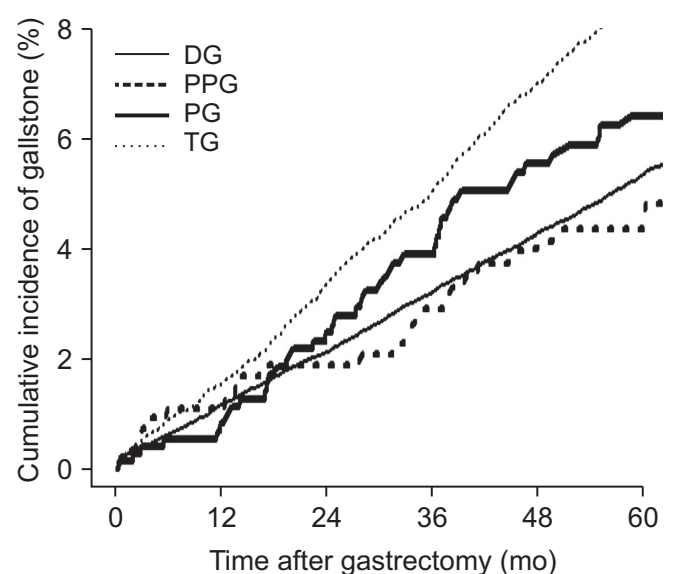

No. at risk

$\begin{array}{lrrrrrr}\text { DG } & 34,730 & 32,853 & 31,008 & 29,481 & 28,181 & 26,964 \\ \text { PPG } & 552 & 517 & 489 & 474 & 454 & 441 \\ \text { PG } & 759 & 687 & 633 & 594 & 557 & 533 \\ \text { TG } & 11,711 & 10,226 & 8,845 & 7,933 & 7,286 & 6,764\end{array}$

No. at risk

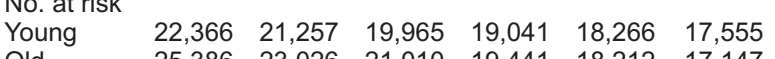

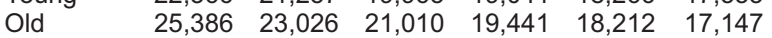

Fig. 1. Cumulative incidence of postgastrectomy gallstone in the whole cohort (A), male and female patients (B), younger and older patients $(\mathrm{C})$, and patients who underwent different types of gastrectomy (D). Younger and older patients were defined as 30-59- and 60-89-year-olds, respectively. DG, distal gastrectomy; PPG, pylorus-preserving distal gastrectomy; PG, proximal gastrectomy; TG, total gastrectomy.

\section{DISCUSSION}

The present study showed that the incidence of gallstones 5 years after gastrectomy was $5.2 \%$. This incidence was about twice as high as the prevalence of gallstones in general Korean population, which was $2.0 \%$ to $3.4 \%$ [15-17]. Meanwhile, in studies involving gastrectomy patients, the incidence in this study was similar or lower than that of the previous studies, which ranged from $5.2 \%$ to $25.7 \%[2-8,18]$.

The difference between the present study and the latter studies may be due to several factors. First, the present study was based on nationwide data whereas the previous studies were single institution-based studies with relatively small study populations $[2,4-8,18]$. This difference is important because the incidence of gallstones after gastrectomy is likely to be influenced by multiple local factors that relate to the institution and the surgeons, including the experience of individual operators, type of operation, type of reconstruction, extent of lymph node dissection, and follow-up protocol. For this reason, it is important to use a large-scale multicenter study to determine the actual incidence (preferably one that is based on nationwide data). Second, the incidence of gallstones after gastrectomy may be low in South Korea because Billroth I anastomosis for reconstruction is more frequently performed in South Korea than in other countries [19,20]. This preference may have helped to prevent gallstone formation because Billroth I anastomosis preserves the food passage through the duodenum [21]. Third, there might exist false negative 
patients in the present study. In general, CT scan is inferior to ultrasonography in detecting gallstones [22]. Therefore, gallstones are might to be missed at the institution in which CT scan is a major follow-up modality rather than ultrasonography. Finally, we found that the annual incidence of gallstones rose steadily during the 5-year follow-up period. This has also been observed by other studies $[2,3,8]$. Therefore, the low incidence rate we recorded may be due in part to the short follow-up duration, and it is likely that we will observe a higher incidence of postgastrectomy gallstone formation if we extend our followup duration.

We found that males and older patients were significantly more likely to develop gallstones. This is consistent with the findings of several studies $[2,5,18]$. However, it remains unclear how these factors shape gallstone formation after gastrectomy. To clarify these underlying pathophysiological mechanisms, further studies are necessary.

Both total gastrectomy and proximal gastrectomy involve the severance of the vagus nerve. By contrast, pyloruspreserving distal gastrectomy involves the preservation of the hepatic branch of the anterior vagus nerve and the right gastric artery [23]. Vagus nerve injury during gastrectomy could increase the tension of the sphincter of Oddi and reduce the contractive function of the gallbladder. This in turn could result in bile stasis and gallstone formation [21,24]. Indeed, in the present study, the gallstone incidence was highest after total gastrectomy, followed by proximal gastrectomy, distal gastrectomy, and pylorus-preserving distal gastrectomy. This is consistent with previous studies that showed that the gallstone incidence is high after total gastrectomy and low after pyloruspreserving distal gastrectomy $[2,3,21,23,24]$. Moreover, the metaanalysis conducted by Chen et al. [21] showed that postoperative gallstone formation occurred less frequently in patients who underwent physiological reconstruction and vagus nerve preservation than in those who did not. Regarding the issues of reconstruction methods, studies showed conflicting results. While some studies reported the irrelevance between the type of reconstruction and the frequency of gallstone formation either in distal gastrectomy or total gastrectomy [7,25], other studies reported the lower incidence of gallstone formation in patients who underwent Billroth I anastomosis (or physiologic reconstruction) than Billroth II or Roux-en-Y anastomosis (or nonphysiologic reconstruction) $[2,3,5,8,26]$. The suggested pathophysiologic mechanism was that exclusion of food passage to duodenum changes the pattern of cholecystokinin secretion, which results in reducing gallbladder contractility and increasing gallstone formation [8].

In the present study, the preservation or resection of the pylorus did not significantly influence the incidence of gallstone formation: $4.8 \%$ of the patients who underwent pylorus-preserving distal gastrectomy and proximal gastrectomy and $5.3 \%$ of the patients who underwent total gastrectomy and distal gastrectomy developed gallstones $(\mathrm{P}=0.506)$. This may reflect the fact that both groups contained patients with vagus nerve injury and duodenal food passage: since the former factor promotes gallstone formation and the latter prevents it, it may not have been possible to detect an effect of pylorus resection relative to pylorus preservation.

It is not well demonstrated yet whether the proportion of the gallstone patients requiring cholecystectomy is affected by the previous gastrectomy or not. However, several studies on the natural history of asymptomatic gallstones report that the mean yearly probability of biliary colic is about $2 \%$ per year $[27,28]$. In the present study, $26 \%$ of the patients who developed gallstone after gastrectomy underwent cholecystectomy during the 5-year follow-up. This is consistent with the results of a systematic review by Gillen et al. [29]. In this context, the present study suggests that the history of gastrectomy may shape the clinical course of gallstones. To elucidate the underlying pathophysiological mechanisms, further studies are warranted.

This study has several limitations. First, we only analyzed the data that were available in the claim forms of the HIRA database and patient selection was based entirely on the ICD-10 code that had been put in by the physician. The medical records of the patients were not reviewed. Thus, it is possible that there were false-positive and false-negative gallstone findings in our cohort. False-positive findings include those patients who already had gallstones before gastrectomy: these cases could not be excluded because ultrasonography was not performed preoperatively. False-negative findings include those patients who developed gallstones after gastrectomy but the stone was missed during the follow-up because ultrasonography was not performed. The second limitation is that a significant number of the patients with postgastrectomy gallstone might be uncounted when the diagnostic code was falsely input by the clinicians. For instance, there might be clinicians who used the diagnostic code of K81.0 (code for acute acalcuous chlecystitis) for gasllstone cholecystitis. In addition, the patients who were diagnosed gallstones or underwent cholecystectomy before gastrectomy must be excluded from the study population. However, due to the lack of the data before January 2007 in HIRA database, such patients were included in the study and the incidence was underestimated in certain degree because the denominator should have been smaller. Last, we could not analyze the influence of clinical factors that could shape gallstone formation on gallstone incidence, including the method used for reconstruction and the extent of lymph node dissection, body mass index, and underlying disease such as diabetes or liver cirrhosis, because the HIRA database does not include such clinical data. More detailed database with long follow-up period is necessary to understand the development of 
gallstone after gastrectomy more comprehensively. Nevertheless, given the fact that the whole population of South Korea was included in this study (i.e., there was no major selection bias), we believe that the present study provides helpful information about gallstone incidence after gastrectomy.

In conclusion, the cumulative incidence of gallstones after gastric resection rose steadily over time and was 5.2\% after 5 years of follow-up. About $26 \%$ of the patients who developed gallstones after gastrectomy had to undergo cholecystectomy. Male sex, an older age, and total gastrectomy were risk factors for the development of gallstones after gastrectomy for gastric cancer. We recommend that patients with these risk factors should be followed up particularly carefully in terms of gallstone formation. To evaluate the incidence of and risk factors for gallstone formation after gastrectomy, well-designed prospective multicenter studies with a large-scale cohort are warranted.

\section{CONFLICTS OF INTEREST}

No potential conflict of interest relevant to this article was reported.

\section{REFERENCES}

1. Oh CM, Won YJ, Jung KW, Kong HJ, Cho H, Lee JK, et al. Cancer statistics in Korea: incidence, mortality, survival, and prevalence in 2013. Cancer Res Treat 2016; 48:436-50.

2. Paik KH, Lee JC, Kim HW, Kang J, Lee YS, Hwang JH, et al. Risk factors for gallstone formation in resected gastric cancer patients. Medicine (Baltimore) 2016;95: e3157.

3. Jun KH, Kim JH, Kim JJ, Chin HM, Park SM. Retrospective analysis on the gallstone disease after gastrectomy for gastric cancer. Gastroenterol Res Pract 2015;2015:827864.

4. Nakamura K, Ogoshi K, Makuuchi H. Clinicopathological study of cholelithiasis following gastric cancer surgery. Eur Surg Res 2005;37:29-35.

5. Park DJ, Kim KH, Park YS, Ahn SH, Park do J, Kim HH. Risk factors for gallstone formation after surgery for gastric cancer. J Gastric Cancer 2016;16:98-104.

6. Akatsu T, Yoshida M, Kubota T, Shimazu M, Ueda M, Otani Y, et al. Gallstone disease after extended (D2) lymph node dissection for gastric cancer. World J Surg 2005;29:182-6.

7. Fukagawa T, Katai H, Saka M, Morita S, Sano T, Sasako M. Gallstone formation after gastric cancer surgery. J Gastrointest Surg 2009;13:886-9.

8. Kobayashi T, Hisanaga M, Kanehiro H, Yamada Y, Ko S, Nakajima Y. Analysis of risk factors for the development of gallstones after gastrectomy. Br J Surg 2005:92:1399-403.

9. Kim J, Cho JN, Joo SH, Kim BS, Lee SM. Multivariable analysis of cholecystectomy after gastrectomy: laparoscopy is a feasible initial approach even in the presence of common bile duct stones or acute cholecystitis. World J Surg 2012;36:638-44.

10. Zhang MJ, Yan Q, Zhang GL, Zhou SY, Yuan WB, Shen HP. Laparoscopic Cholecystectomy in Patients With History of Gastrectomy. JSLS 2016;20(4). pii: e2016.00075.

11. Sasaki A, Nakajima J, Nitta H, Obuchi T, Baba S, Wakabayashi G. Laparoscopic cholecystectomy in patients with a history of gastrectomy. Surg Today 2008;38:790-4.

12. Kwon AH, Inui H, Imamura A, Kaibori M, Kamiyama Y. Laparoscopic cholecyzstectomy and choledocholithotomy in patients with a previous gastrectomy. J Am Coll Surg 2001;193:614-9.

13. Bernini M, Bencini L, Sacchetti R, Marchet A, Cristadoro L, Pacelli F, et al. The Cholegas Study: safety of prophylactic cholecystectomy during gastrectomy for cancer: preliminary results of a multicentric randomized clinical trial. Gastric Cancer 2013;16:370-6.

14. Seo GH, Chai YJ, Choi HJ, Lee KE. Incidence of permanent hypocalcaemia after total thyroidectomy with or without central neck dissection for thyroid carcinoma: a nationwide claim study. Clin Endocrinol (Oxf) 2016;85:483-7.

15. Chung YJ, Park YD, Lee HC, Cho HJ, Park KS, Seo EH, et al. Prevalence and risk factors of gallstones in a general health screened population. Korean J Med 2007; 72:480-90.

16. Jung HW, Chun KS, Kim YS, Kim MH, Choi H. Prevalence of gallstones in Korean. J Korean Acad Fam Med 1992;13:581-91.

17. Lee JK, Rhee PL, Lee JH, Lee KT, Choi SH, Noh JH, et al. Prevalence and risk factors of gallstone in health screening people. Korean J Gastroenterol 1997:29:85-92.

18. Lai SL, Yang JC, Wu JM, Lai IR, Chen CN, Lin MT, et al. Combined cholecystectomy in gastric cancer surgery. Int J Surg 2013; 11:305-8.

19. Information Committee of Korean Gastric Cancer Association. Korean Gastric Cancer Association nationwide survey on gastric cancer in 2014. J Gastric Cancer 2016;16: 131-40.

20. Jeong O, Park YK. Clinicopathological features and surgical treatment of gastric cancer in South Korea: the results of 2009 nationwide survey on surgically treated gastric cancer patients. J Gastric Cancer 2011;11:69-77.

21. Chen XJ, Li N, Huang YD, Ren S, Liu F, Chen $\mathrm{L}$, et al. Factors for postoperative gallstone occurrence in patients with gastric cancer: a meta-analysis. Asian Pac J Cancer Prev 2014:15:877-81. 
22. Demehri FR, Alam HB. Evidence-based management of common gallstonerelated emergencies. J Intensive Care Med 2016;31:3-13.

23. Suh YS, Han DS, Kong SH, Kwon S, Shin CI, Kim WH, et al. Laparoscopyassisted pylorus-preserving gastrectomy is better than laparoscopy-assisted distal gastrectomy for middle-third early gastric cancer. Ann Surg 2014:259:485-93.

24. Hauters P, de Neve de Roden A, Pourbaix A, Aupaix F, Coumans P, Therasse G. Cholelithiasis: a serious complication after total gastrectomy. Br J Surg 1988;75:
899-900.

25. Inokuchi M, Kojima K, Yamada H, Kato K, Hayashi M, Motoyama K, et al. Longterm outcomes of Roux-en-Y and Billroth-I reconstruction after laparoscopic distal gastrectomy. Gastric Cancer 2013;16:67-73. 26. Nunobe S, Okaro A, Sasako M, Saka M, Fukagawa T, Katai H, et al. Billroth 1 versus Roux-en-Y reconstructions: a quality-oflife survey at 5 years. Int J Clin Oncol 2007;12:433-9.

27. Gracie WA, Ransohoff DF. The natural history of silent gallstones: the innocent gallstone is not a myth. N Engl J Med
1982;307:798-800.

28. Sakorafas GH, Milingos D, Peros G. Asymptomatic cholelithiasis: is cholecystectomy really needed? A critical reappraisal 15 years after the introduction of laparoscopic cholecystectomy. Dig Dis Sci 2007:52:1313-25.

29. Gillen S, Michalski CW, Schuster T, Feith M, Friess H, Kleeff J. Simultaneous/ Incidental cholecystectomy during gastric/ esophageal resection: systematic analysis of risks and benefits. World J Surg 2010; 34:1008-14. 